\title{
Editorial
}

\section{Taking the long view: a geological contribution to understanding the causes of global glaciation}

Misen odelling future climates is both a very difficult task and one of key importance to our future wellbeing. Why then would we want to make it more difficult by shortening our perspective to the most recent period, ignoring historical data that would provide the long perspective on key processes? Palaeoenvironmental research has resulted in important advances in our understanding of global changes in oceanic, atmospheric and biotic systems during glaciation and the onset of the current glacial epoch. However, few palaeoenvironmental studies extend farther back than half a million years, and, with the exception of the recently completed Cape Roberts drilling project, vanishingly few consider events prior to the Eocene (55-38 million years ago).

We run the risk of throwing the baby out with the bath water if we ignore the older geological record. Preserved there is evidence for at least four major glacial epochs as intense as the current one (Pleistocene-Holocene: between 2.6 and 1.8 million years ago to today). Some periods exceeded 40 million years in duration, and, although controversial, some scientists would argue that the rock record indicates even an ice-house Earth (glaciation from pole to equator) at times.

The current epoch (the Holocene: $c$. 10 thousand years ago to today) is often referred to as "postglacial", implying somehow that the "ice age" is over. If the older geological record tells us anything, it is that the "ice age" has hardly begun. We will miss a wealth of information on the evolution and potential intensity of glacial epochs if we do not consider research into the pre-Pleistocene and preEocene geological and glacial record. The data from hard-rock geology covers a much greater time span than the Holocene, making it more likely that we will see just how extreme the climate has been, as well why planet-scale glaciation occurs in the first place, something that is not yet understood.

Antarctica's role as a possible nucleation point for global glaciation can be understood better by looking at its tectonic and palaeoenvironmental evolution over the last 180 million years. This was the period when surrounding fragments of the Gondwana supercontinent were progressively stripped away, leaving Antarctica marooned at the pole. Why, for example, did the last peak of glaciation, c. 280 million years ago, occur at a time of maximum continental agglomeration, whereas the current one coincides with an epoch of major dispersal of the continents?

Good models need good data. By restricting ourselves to the last 2 million years, or even the last 40 million, we are hobbling our chances of fully understanding the global glaciation phenomenon. It is imperative that we cast our glance further back and look at the Earth System through the whole of geological time, rather than just the most recent few percent of it.

The current tendency is to focus research on the epoch for which we have the most complete records, i.e. the Pleistocene-Holocene. This is a bit like searching for your keys under a lamp-post because it's brighter there! It may be easier to see, and we will certainly gain a good understanding of glacial processes and short term $(<100000$ years) climatic fluctuations but that is not the whole story. It seems unlikely that the ultimate understanding of the cause of glaciation will be ours until we start feeling our way out into the unexplored darkness, and that means more wholeheartedly investigating the deep geological past.

Alan VAUGHaN 